\title{
The binding of orally dosed hydrophobic active pharmaceutical ingredients to casein micelles in milk
}

\author{
M. Cheema, ${ }^{*}$ A. N. Hristov, $†$ and F. M. Harte ${ }^{* 1}$ \\ *Department of Food Science, and \\ †Department of Animal Science, The Pennsylvania State University, University Park 16802
}

\begin{abstract}
Casein proteins $\left(\alpha_{\mathrm{S1}^{-}}, \alpha_{\mathrm{S} 2^{-}}, \beta\right.$ - and $\kappa$-casein $)$ account for $80 \%$ of the total protein content in bovine milk and form casein micelles (average diameter $=130 \mathrm{~nm}$, approximately $10^{15}$ micelles $/ \mathrm{mL}$ ). The affinity of native casein micelles with the 3 hydrophobic active pharmaceutical ingredients (API), meloxicam [351.4 g/mol; log $\mathrm{P}=3.43$; acid dissociation constant $\left.\left(\mathrm{p} K_{\mathrm{a}}\right)=4.08\right]$, flunixin $\left(296.2 \mathrm{~g} / \mathrm{mol} ; \log \mathrm{P}=4.1 ; \mathrm{p} K_{\mathrm{a}}=5.82\right)$, and thiabendazole $\left(201.2 \mathrm{~g} / \mathrm{mol} ; \log \mathrm{P}=2.92 ; \mathrm{p} K_{\mathrm{a}}=4.64\right)$, was evaluated in bovine milk collected from dosed Holstein cows. Native casein micelles were separated from raw bovine milk by mild techniques such as ultracentrifugation, diafiltration, isoelectric point precipitation $(\mathrm{pH}$ 4.6), and size exclusion chromatography. Acetonitrile extraction of hydrophobic API was then done, followed by quantification using HPLC-UV. For the API or metabolites meloxicam, 5-hyroxy flunixin and 5-hydroxy thiabendazole, $31 \pm 3.90,31 \pm 1.3$, and $28 \pm 0.5 \%$ of the content in milk was associated with casein micelles, respectively. Less than $\sim 5.0 \%$ of the recovered hydrophobic API were found in the milk fat fraction, and the remaining $\sim 65 \%$ were associated with the whey/ serum fraction. A separate in vitro study showed that $66 \pm 6.4 \%$ of meloxicam, $29 \pm 0.58 \%$ of flunixin, $34 \pm$ $0.21 \%$ of the metabolite 5 -hyroxy flunixin, $50 \pm 4.5 \%$ of thiabendazole, and $33 \pm 3.8 \%$ of metabolite 5 -hydroxy thiabendazole was found partitioned into casein micelles. Our study supports the hypothesis that casein micelles are native carriers for hydrophobic compounds in bovine milk.
\end{abstract}

Key words: casein micelle, hydrophobic, meloxicam, flunixin, thiabendazole

\section{INTRODUCTION}

Bovine milk proteins are composed of $80 \%$ casein proteins $\left(\alpha_{\mathrm{S1}^{-}}, \alpha_{\mathrm{S}_{2}}, \beta-\right.$, and $\left.\kappa-\mathrm{CN}\right)$ and $20 \%$ whey pro-

Received January 23, 2017.

Accepted June 22, 2017.

${ }^{1}$ Corresponding author: fede@psu.edu teins (mainly $\beta-\mathrm{LG}, \alpha-\mathrm{LA}$, and BSA). Casein proteins exist in the form of colloidal particles of $\sim 130 \mathrm{~nm}$ average diameter, known as casein micelles. Although controversy remains on the casein micelle nanostructure, it is known that calcium phosphate nanoclusters bind to phosphoseryl residues of $\alpha_{S^{-}}$and $\beta$-CN, forming the internal core of the micelles, and $\kappa$-CN predominantly exist at the surface, providing steric and electrostatic stability against micellar aggregation (Dalgleish, 2011; de Kruif et al., 2012). The agreed biological role of casein micelles is to transport calcium from mother to young, prevent calcification of the mammary gland, and provide AA for the growth and development of the neonate (Fox and Brodkorb, 2008; Holt et al., 2013). Environmental factors, including $\mathrm{pH}$, solvent, and pressure, were explored extensively to dissociate and reassemble casein micelles to bind and deliver various hydrophobic (poorly water-soluble) nutraceuticals. These modified casein micelles were used to nonspecifically bind vitamin $\mathrm{D}_{2}$, curcumin, and ritonavir, among others (Semo et al., 2007; Pan et al., 2014; Corzo-Martínez et al., 2015).

Whereas several reports demonstrated that the 2 major whey proteins ( $\beta$-LG and $\alpha-\mathrm{LA}$ ) have binding sites for hydrophobic molecules (e.g., vitamin A, D, palmitic acid; Puyol et al., 1991; Forrest et al., 2005), the native binding properties of the casein micelles are not well characterized. The casein micelles have an open structure with serum filled channels and cavities accessible by small molecules (Dalgleish, 2011; Trejo et al., 2011). The reversible dissociation and association of $\beta$-CN on temperature fluctuations provides evidence for the accessibility of the internal core and potential for sites with affinity toward hydrophobic probes (Dalgleish, 2011; Atamer et al., 2017). A recent report demonstrated that native casein micelles isolated from raw milk exhibited a stronger binding affinity toward hydrophobic compounds (MW <900 Da, log P >4) versus hydrophilic compounds (Cheema et al., 2015). These hydrophobic compounds were identified as phospholipids, including sphingomyelins, phosphatidylcholines, and phosphatidylethanolamines. A separate study conducted on casein micelles from commercial 
ultrapasteurized milk showed that up to $40 \%$ vitamin A added to fortify milk eventually bound to casein micelles (Mohan et al., 2013).

Although fat-soluble compounds appearing in milk are believed to associate with the fat fraction, we hypothesized that the open structure of native casein micelles provides a better environment for the binding and transportation for hydrophobic molecules present in mammalian milk. Very few studies have been conducted to determine the distribution of hydrophobic active pharmaceutical ingredients (API; e.g., antibiotics, nonsteroidal anti-inflammatory drugs, anthelmintics) in cow milk components (Cerkvenik et al., 2004; Hakk et al., 2016; Shappell et al., 2017) , and no studies have examined the role of native casein micelles. Furthermore, the studies that have been completed were done by spiking pasteurized milk samples in vitro, resulting in a lack of information regarding in vivo distribution of the parent API and their major metabolites.

The main objective of the current study was to determine the binding ability of casein micelles in their native state using hydrophobic API appearing in bovine milk from dosed animals. As proof of concept, the partitioning of model hydrophobic API into native casein micelles was quantified using weakly acidic meloxicam, flunixin, and weakly basic thiabendazole. Meloxicam and flunixin are commonly used nonsteroidal antiinflammatory API and are known to appear in milk of dosed cows (Jedziniak et al., 2009a; Kissell et al., 2012); thiabendazole is an anthelmintic API used for deworming affected cows (Su et al., 2003; Chen et al., 2010). Casein micelles are the major proteins in bovine milk and the building blocks of dairy foods, including cheese and yogurt. Understanding the role played by the casein micelles in binding hydrophobic API appearing in dosed animals would be helpful to limit consumer exposure. The binding ability of native casein micelles can potentially be used to protect and deliver hydrophobic nutraceuticals in dairy foods.

\section{MATERIALS AND METHODS}

This study was approved by The Pennsylvania State University (University Park, PA) Institutional Animal Care and Use Committees.

\section{Criteria for Selection of API}

The API were selected based on (1) approval for use in dairy animals; (2) withdrawal time in milk in API-dosed cows; (3) range of hydrophobicity ( $\log \mathrm{P}=$ 2.92-4.1) to understand the effect of hydrophobicity on the partition to casein micelles. The information regarding approved API and their withdrawal times in bovine milk was obtained from Food Animal Residue Avoidance Databank (2016).

The model API were selected based on their hydrophobicity, defined by $\log \mathrm{P}$ values ( $\mathrm{P}$ being partition in organic or aqueous phase); however, certain classes of API are ionizable at milk physiological $\mathrm{pH} 6.8$, and the hydrophobicity of such API is better characterized by $\log \mathrm{D}$ values instead of $\log \mathrm{P}$ values. The $\log \mathrm{D}$ at specific $\mathrm{pH}$ can be calculated by using the $\log \mathrm{P}$ and acid dissociation constant $\left(\mathbf{p} \boldsymbol{K}_{\mathrm{a}}\right)$ values for the API in following equations:

$$
\begin{gathered}
\log \mathrm{D}_{\text {acid }}=\log \mathrm{P}+\log \left[1 /\left(1+10^{\mathrm{pH}-\mathrm{p} K a}\right)\right],[1] \text { and } \\
\log \mathrm{D}_{\text {base }}=\log \mathrm{P}+\log \left[1 /\left(1+10^{\mathrm{pKa}-\mathrm{pH}}\right)\right],
\end{gathered}
$$

The $\log \mathrm{P}$ and $\mathrm{p} K_{\mathrm{a}}$ values for the API were obtained from PubChem Database (https://pubchem.ncbi.nlm .nih.gov) and $\mathrm{p} K_{\mathrm{a}}$ values were obtained from Drug Bank database (http://www.drugbank.ca/) and using appropriate software (ChemAxon, Budapest, Hungary).

\section{Milk Sample Collection and Preparation}

In Vivo Study. Three Holstein cows in midlactation were used for meloxicam, 3 separate cows were used for flunixin and 2 cows were used for thiabendazole in vivo treatments. The average BW of the cows treated with meloxicam, flunixin and thiabendazole was $665 \pm 8$, $572 \pm 40$, and $614 \pm 55 \mathrm{~kg}$, respectively. All the cows were fed on same TMR diet. Raw milk samples containing meloxicam residues were collected from cows (3 replications) from The Pennsylvania State University Research and Teaching Dairy Center (University Park) at 12-h intervals that received a single permissible oral dose of $1 \mathrm{mg} / \mathrm{kg}$ of BW of meloxicam (Table 1; Unichem Laboratories Ltd., Mumbai, India). Preliminary analysis conducted in our laboratory showed maximum concentration at $12 \mathrm{~h}$ for meloxicam, $36 \mathrm{~h}$ for flunixin, and $12 \mathrm{~h}$ for thiabendazole. Raw milk containing the metabolite 5-hydroxy flunixin was collected from Holstein cows (3 replications) treated with permissible intravenous doses of $2.2 \mathrm{mg} / \mathrm{kg}$ of $\mathrm{BW}$ of flunixin meglumine (Table 1; Banamine, Merck Animal Health, Madison, NJ) for 3 consecutive days. The milk was collected at $36 \mathrm{~h}$ after the last administered dose of flunixin. Raw milk samples containing metabolite 5 -hydroxy thiabendazole were collected from Holstein cows (2 replications) $12 \mathrm{~h}$ after a single oral dose of $67 \mathrm{mg} / \mathrm{kg}$ of BW of thiabendazole (Table 1; Dorneyville Compounding Pharmacy, Allentown, PA). The raw milk samples were collected directly from each cow, transported on ice, 
Table 1. Withdrawal times and physicochemical properties of hydrophobic API ${ }^{1}$

\begin{tabular}{|c|c|c|c|c|c|c|c|}
\hline Model hydrophobic API & Class of API & $\begin{array}{c}\text { Molecular } \\
\text { weight (Da) }\end{array}$ & $\begin{array}{l}\text { Solubility } \\
\text { (mg/L) }\end{array}$ & $\log \mathrm{P}^{2}$ & $\mathrm{p} K_{\mathrm{a}}^{3}$ & $\begin{array}{c}\log \mathrm{D}^{(4,5)} \\
(\mathrm{pH} 6.8)\end{array}$ & $\begin{array}{l}\text { Withdrawal } \\
\text { time }^{6}(\mathrm{~h})\end{array}$ \\
\hline Meloxicam & Weakly acidic & 351.4 & 7.15 & 3.43 & 4.08 (acidic) & 0.71 & 96 \\
\hline Thiabendazole & Weakly basic & 201.2 & 50 & 2.92 & 4.64 (basic) & 2.92 & 96 \\
\hline Flunixin & Weakly acidic & 296.2 & 0.85 & 4.1 & 5.82 (acidic) & 3.08 & 36 \\
\hline $\begin{array}{l}\text { 5-Hydroxy flunixin } \\
\text { (5OH-FLU) }\end{array}$ & Weakly acidic & 312.2 & - & 3.7 & - & 1.93 & 36 \\
\hline
\end{tabular}

${ }^{1}$ API $=$ active pharmaceutical ingredient.

${ }^{2} \log P$-values were accessed from PubChem (https://pubchem.ncbi.nlm.nih.gov) on January 26, 2015.

${ }^{3} \mathrm{p} K_{\mathrm{a}}$ values were accessed from Drug Bank (https://www.drugbank.ca/) on January 26, 2015.

${ }^{4} \log \mathrm{D}$ values were calculated using $\log P$ and $\mathrm{p} K_{\mathrm{a}}$ values (see above).

${ }^{5} \log \mathrm{D}$ values were predicted using ChemAxon software (https://www.chemaxon.com/; ChemAxon, Budapest, Hungary).

${ }^{6}$ Withdrawal times are obtained from FARAD website (http://www.farad.org/), accessed on Aug. 20, 2014.

and stored at $4^{\circ} \mathrm{C}$. The fat was removed from the raw milk by centrifugation at $20^{\circ} \mathrm{C}(6,414 \times g$ for $20 \mathrm{~min})$ followed by storage at $-20^{\circ} \mathrm{C}$ until analysis. All the analyses were performed within $48 \mathrm{~h}$ of sample collection. Four different techniques were used to separate casein micelles from raw milk - ultracentrifugation, size exclusion chromatography, diafiltration/ultrafiltration, and isoelectric point precipitation of caseins - with the exception of size exclusion chromatography not used for the determination of flunixin and thiabendazole.

In Vitro Study. The whole raw milk obtained from cows in midlactation was fortified with 5 hydrophobic API $(300 \mu \mathrm{g} / \mathrm{L})$ with partition coefficient of $\log \mathrm{P}=$ 3.43 for meloxicam, $\log \mathrm{P}=4.1$ for flunixin and $\log \mathrm{P}=$ 3.7 for its metabolite 5-hydroxyflunixin (5-OH-FLU), and $\log \mathrm{P}=2.92$ for thiabendazole and $\log \mathrm{P}=2.1$ for its metabolite 5-hydroxythiabendazole (5-OH-TBZ; Table 1). The concentration was arbitrarily set below the solubility limit of these API. Milk for fortification was obtained from the same cows used in the in vivo studies. The samples were spiked with the API and stirred at $25^{\circ} \mathrm{C}$ for $1 \mathrm{~h}$.

\section{Ultracentrifugation}

The whole raw milk (20 mL/centrifuge tube) was subjected to ultracentrifugation $(100,000 \times g$ for $1 \mathrm{~h}$; Sorvall MTX 150, S50-A 2036, Thermo-Fisher Scientific, Waltham, MA) at $20^{\circ} \mathrm{C}$ to separate 3 fractions: fat, whey (serum), and casein pellet. The fractions were weighed and stored at $-20^{\circ} \mathrm{C}$ until analysis.

\section{Size Exclusion Chromatography}

The raw skim milk was subjected to size exclusion chromatography to separate casein micelles using a gel filtration column (Superdex 200 prep grade, GE
Life Sciences, Piscataway, NJ) connected to an AKTA fast-performance liquid chromatography unit (GE Life Sciences) using a previously reported method (Cheema et al., 2015). Briefly, protein-free serum from the same animal was used as the mobile phase in size exclusion chromatography to ensure a native environment for the casein micelles. The protein-free serum was prepared by tangential flow cross-filtration of skim milk using a regenerated cellulose membrane with a $3-\mathrm{kDa}$ molecular weight cut off (PLBC Prep scale TFF Cartridge, Millipore, Billerica, MA). The protein-free serum was preserved in $0.07 \% \mathrm{NaN}_{3}$ to prevent microbial growth and stored at $4^{\circ} \mathrm{C}$ until size exclusion chromatography. Two milliliters of raw skim milk was loaded onto the column and proteins were eluted using a flow rate of 1.0 $\mathrm{mL} / \mathrm{min}$ for 2 column volumes $(240 \mathrm{~mL})$ and collected in $30-\mathrm{mL}$ fractions. The elution of proteins was monitored using a UV absorbance detector set at $280 \mathrm{~nm}$. A total of 4 replications were done for each sample. The casein micelle fractions were collected, freeze-dried, and stored at $-20^{\circ} \mathrm{C}$ for the further analysis of the API by HPLC.

\section{Diafiltration}

Fifty milliliters of raw skim milk was subjected to diafiltration using a composite regenerated cellulose membrane with a $300-\mathrm{kDa}$ molecular weight cut off (Pellicon XL cassette, Millipore) connected to a peristaltic pump to obtain a casein micelle concentrate. Protein-free serum was used to wash the casein micelles in their native environment. Diafiltration was performed by subjecting the raw skim milk to 6 cycles of removing and replacing the protein-free serum to ensure the removal of low-molecular-weight residues in the serum phase of skim milk and retain those associated with the casein micelles. After exhaustive diafiltration, the 
concentrated casein micelles (retentate) were collected and stored at $-20^{\circ} \mathrm{C}$ for further analysis of API residue concentration.

\section{Isoelectric Point Precipitation}

The casein micelles were precipitated at the isoelectric point by adjusting the $\mathrm{pH}$ of $20 \mathrm{~mL}$ of raw skim milk to 4.6 using $\mathrm{HCl}$. The precipitates were washed and centrifuged at $1,000 \times g$ for $3 \mathrm{~min}$ at $20^{\circ} \mathrm{C}$ for 6 replicates. The casein micelle precipitates were stored at $-20^{\circ} \mathrm{C}$ for further API residue analysis.

\section{Standards and Chemicals}

Standards of meloxicam, flunixin, thiabendazole, and 5-OH-TBZ were purchased from Sigma-Aldrich (St. Louis, MO) and standard 5-OH-FLU was purchased from Santa Cruz Biotechnology Inc. (Dallas, TX). Acetonitrile (HPLC grade), $\mathrm{MeOH}$ (HPLC grade), acetic acid (HPLC grade), ammonium acetate $\left(\mathrm{CH}_{3} \mathrm{COONH}_{4}\right.$, HPLC grade), and $\mathrm{NaCl}$ were purchased from VWR international (Bridgeport, NJ).

\section{Standard Solutions and Calibrations}

Stock-standard solutions with a $1,000 \mu \mathrm{g} / \mathrm{mL}$ concentration of meloxicam, 5-OH-FLU, and 5-OH-TBZ were prepared by dissolving $10 \mathrm{mg}$ of analytical standard in $10 \mathrm{~mL}$ of methanol. The intermediate-standard solutions $(100 \mu \mathrm{g} / \mathrm{mL})$, were prepared by diluting suitable aliquots of the stock-standard solutions, which were further diluted to prepare working-standard solutions $(10 \mu \mathrm{g} / \mathrm{mL})$. The blank milk samples were fortified with suitable amounts of working-standard solutions $(10 \mu \mathrm{g} / \mathrm{mL})$, to prepare calibration standards of 10,25 , $50,100,150,300$, and $600 \mu \mathrm{g} / \mathrm{L}$ for all $3 \mathrm{API}$.

\section{Sample Extraction for Hydrophobic API}

The casein micelle preparations from 4 different separation protocols were thawed and reconstituted by adding appropriate amount of water and extracted using methods by Jedziniak et al. (2009b). Briefly, the whole raw milk, skim raw milk, fat, whey (serum), and casein proteins were subjected to extractions for API using $20 \mathrm{~mL}$ of acetonitrile and $4 \mathrm{~g}$ of sodium chloride, followed by vigorous vortexing for $1 \mathrm{~min}$ and centrifugation $\left(3,200 \times g, 20 \mathrm{~min},-5^{\circ} \mathrm{C}\right)$. The supernatant was transferred to a glass test tube and evaporated to dryness using a continuous nitrogen stream at $40^{\circ} \mathrm{C}$. The dry residue was reconstituted using $250 \mu \mathrm{L}$ of 0.05 $M$ ammonium acetate ( $\mathrm{pH}$ 5.0):acetonitrile:methanol
$(1+1+1 ; \mathrm{vol})$, transferred to HPLC vials, centrifuged $\left(16,000 \times g, 5 \mathrm{~min}, 4^{\circ} \mathrm{C}\right)$, and $50 \mu \mathrm{L}$ was injected to the HPLC column.

\section{Chromatographic Conditions}

The quantitative analysis of the API extracted from milk samples and fractions was performed using an HPLC system (pump model LC-10 ADvp, Shimadzu, Columbia, MD) equipped with a degasser, autosampler, and UV-Vis diode array detector, controlled by LC Solutions Workstation software (Shimadzu). The chromatographic separations were performed using a reversed-phase C18 column (Supercosil LC-18, $25 \mathrm{~cm}$ $\times 4.6 \mathrm{~mm}, 5 \mu \mathrm{m}$, Supelco Inc., Bellefonte, PA). The column was conditioned with a mobile phase consisting of $90 \% 0.05 \mathrm{M}$ ammonium acetate (solvent A), with $\mathrm{pH}$ adjusted to 5.0 using acetic acid and $10 \%$ acetonitrile (solvent B) at flow rate of $1.2 \mathrm{~mL} / \mathrm{min}$. The gradient elution was applied for 25 min with $10 \%$ of solvent B held for $3 \mathrm{~min}$, increased to $40 \%$ at $10 \mathrm{~min}$, increased to $60 \%$ at $12 \mathrm{~min}$, held at $60 \%$ for $3 \mathrm{~min}$, and reduced to $10 \%$ at $22 \mathrm{~min}$ and, for next $3 \mathrm{~min}$, the column was re-equilibrated with $10 \%$ solvent $\mathrm{B}$. The detector was programmed to monitor the elution of the API at an absorbance wavelength of $365 \mathrm{~nm}$ for meloxicam (elution time $12.4 \mathrm{~min}$ ), $290 \mathrm{~nm}$ for flunixin (elution time 14.2 min) and metabolite 5-OH-FLU (marker metabolite; elution time $13.1 \mathrm{~min}$ ), and $292 \mathrm{~nm}$ for thiabendazole (elution time $11.8 \mathrm{~min}$ ) and $318 \mathrm{~nm}$ for $5-\mathrm{OH} \_\mathrm{TBZ}$ (major metabolite; elution time $9.2 \mathrm{~min}$ ).

\section{Statistical Analysis}

The statistical differences were evaluated by ANOVA followed by Tukey's honest significant difference test $(P<0.05)$. Data were analyzed as completely randomized designs using SAS (version 9.4, SAS institute, Inc. Cary, NC). Average values were calculated using 3 replications (cows) each for meloxicam and flunixin, and 2 replications (cows) for thiabendazole.

\section{RESULTS AND DISCUSSION}

\section{In Vitro Association}

The HPLC analysis of fractions of whole raw milk showed that $66 \pm 6.4 \%$ of meloxicam, $29 \pm 0.58 \%$ of flunixin, and $50 \pm 4.5 \%$ thiabendazole added to milk associated with native casein micelles. The percentages were calculated corresponding to the total concentration of the API present in whole raw milk. The partition into the whey fraction of raw milk was $21 \pm 8.0 \%$ 
for meloxicam, $54 \pm 2.1 \%$ for flunixin, and $29 \pm 3.1 \%$ for thiabendazole. Contrary to expected strong binding to the milk fat globules, the fat fraction of raw bovine milk showed little association with the 3 hydrophobic API tested in the current experiment. The content of the hydrophobic active ingredients found to be associated with the fat fraction of fortified raw milk was $11 \pm$ $0.9,13 \pm 0.15$, and $18 \pm 2.9 \%$ for meloxicam, flunixin, and thiabendazole, respectively.

The results for flunixin and thiabendazole were compared with their metabolites, 5-OH-FLU and 5-OHTBZ, fortified in raw whole milk. Both 5-OH-FLU and 5-OH-TBZ are the major marker metabolites for in vivo studies; hence, an in vitro study by fortifying raw whole milk with the metabolites was also conducted. The percentage of 5-OH-FLU found associated with fat, whey, and casein micelles, was $11 \pm 1.1,53 \pm 2.4$, and $34 \pm 0.2 \%$, respectively. Although the 5-OH-FLU was expected to be less hydrophobic $(\log \mathrm{D}=1.93$ at $\mathrm{pH}$ 6.8) as compared with flunixin, the percentages associated with the milk components followed similar trends as flunixin. The partition of 5-OH-TBZ into fat, whey, and casein micelles was $2.7 \pm 0.14,62 \pm 0.04$, and $35 \pm 5.4 \%$, respectively. Although the majority of thiabendazole was found in casein proteins (50\%), its hydroxylated metabolite was mainly concentrated in the whey (serum) fraction. The distribution of $5-\mathrm{OH}-$ TBZ into whey aqueous phase can be attributed to either binding to whey proteins or enhanced aqueous solubility of the metabolite in its free form due to the presence of hydroxyl groups.

Based on their $\mathrm{p} K_{\mathrm{a}}$ values, certain active ingredients undergo ionization at the physiological $\mathrm{pH}$ of milk (6.6 to 6.8). Meloxicam and flunixin are weakly acidic API with $\mathrm{p} K_{\mathrm{a}}$ values of 4.08 and 5.82 , respectively, and exist as negatively charged species at $\mathrm{pH}$ 6.8. Thiabendazole is a weakly basic API, with $\mathrm{p} K_{\mathrm{a}} 4.64$ (basic), and is not ionized at $\mathrm{pH}$ 6.8. The distribution coefficients (log D) calculated using equations [1] and [2] at $\mathrm{pH} 6.8$ provided information on the hydrophobicity of the active ingredients at milk's native $\mathrm{pH}$. Despite different $\log \mathrm{D}$ values for meloxicam (0.71) and thiabendazole (2.92; Table 1), similar distribution trends were found for both API, with their majority concentration partitioning into casein proteins, followed by the whey and fat fractions. In spite of the strong hydrophobicity of flunixin (log $\mathrm{D}=3.08$ ), only $\sim 30 \%$ flunixin was found associated with the casein micelles with majority showing up in the whey (serum) fraction. Whereas the hydroxylated metabolites of flunixin and thiabendazole are slightly hydrophilic compared with their parent compounds, no significant differences were found between the distribu- tion of flunixin and its metabolite 5-OH-FLU; however, thiabendazole showed significantly different distribution as compared with its metabolite. The differences in partitioning among the 3 active ingredients could be attributed to the differences in functional groups involved in interactions with the milk components. However, the effect of differences in chemical structure was found only in the in vitro studies. Also, in the in vitro studies, the milk was fractionated after $1 \mathrm{~h}$ of stirring at room temperature $\left(\sim 25^{\circ} \mathrm{C}\right)$, which can affect the distribution equilibrium of the API among the milk fractions. This is further discussed in terms of compositional changes of casein micelles induced by different temperatures in comparison to the in vivo study below.

The overall in vitro study results showed that the majority of meloxicam and thiabendazole partitioned into casein proteins, whereas the majority of flunixin, $5-\mathrm{OH}-$ FLU, and 5-OH-TBZ were found in the whey (serum phase) of milk, with less than $20 \%$ of all API found associated with the fat fraction. The whey (serum) fraction is the aqueous phase of milk containing whey proteins (e.g., $\beta$-LG and $\alpha$-LA), which possess binding affinities toward hydrophobic compounds (Livney, 2010; Kimpel and Schmitt, 2015). The API appearing in the serum phase either preferably bound to the whey proteins or remained suspended in free form in the aqueous phase. The binding affinities exclusively toward whey proteins were not investigated in the scope of the current study. Previously reported in vitro studies conducted using thiabendazole showed $47 \%$ of the API partitioning into casein curds and $54 \%$ into whey serum, of which only $12 \%$ was associated with whey proteins (Shappell et al., 2017). The favorable retention of thiabendazole by the casein curds could be explained by the binding of the API to casein micelles but also by the API physical entrapment in the gel matrix.

\section{In Vivo Association}

The in vivo study was done to determine the distribution of the low-molecular-weight hydrophobic API under physiological conditions. The raw milk obtained from the cows dosed with 3 API (i.e., meloxicam, flunixin, and thiabendazole) was subjected to ultracentrifugation to separate the fat, whey (serum), and casein protein fractions. In whole milk collected from the dosed cows, $281.7 \pm 3.0 \mu \mathrm{g} / \mathrm{L}$ of meloxicam was recovered after $12 \mathrm{~h}$ of dosing. Further analysis of milk components obtained by ultracentrifugation showed less than $5 \%$ of meloxicam associated with fat with the majority showing up in whey $(52 \pm 0.76 \%)$ and casein micelles (31 $\pm 3.9 \%$; Figures 1 and 2). Analysis of casein micelles 
obtained by diafiltration and size exclusion chromatography also showed a similar percentage of meloxicam association to casein micelles $(26 \pm 1.5$ and $27 \pm 3.3 \%$, respectively). The casein proteins isolated using isoelectric precipitation $(\mathrm{pH}=4.6)$ showed significantly higher association with meloxicam $(54 \pm 0.02 \%)$ as compared with other 3 methods (Figure 1). This can be attributed to increased concentration of unionized meloxicam at $\mathrm{pH} 4.6$ due to protonation ( $\left.\mathrm{p} K_{\mathrm{a}} 4.08\right)$, resulting in increase of hydrophobic interactions with casein proteins. Meloxicam is a hydrophobic API with $\log \mathrm{P}$ value of 3.43 and was expected to show preferred partition into the fat fraction of milk. However, meloxicam is a weakly acidic API with $\mathrm{p} K_{\mathrm{a}}$ value of 4.08 , resulting in reduced lipophilicity of the API, as $\log \mathrm{P}$ value of 3.4 decreased to $\log \mathrm{D}$ value of 0.71 due to ionization of the API at pH 6.8 (Table 1). The interactions of ionized meloxicam with the casein micelles were attributed to the combination of electrostatic and hydrophobic interactions with the charged and hydrophobic domains present in the internal structure of the casein micelles. The $\sim 52 \%$ recovery from whey was either due to the negatively charged free form of meloxicam in aqueous phase or the association to whey proteins known to bind hydrophobic probes. Further separation of whey proteins from serum would be needed to investigate the complete partition of API into whey proteins. The strong difference found in the partition of meloxicam to casein proteins in the in vitro versus in vivo studies ( $\sim 66$ vs. $\sim 30 \%$, respectively; Figure 2 ) was partially due to the equilibration time taken by the API to partition into casein micelles of the raw bovine milk. The distribution of API in milk components depends

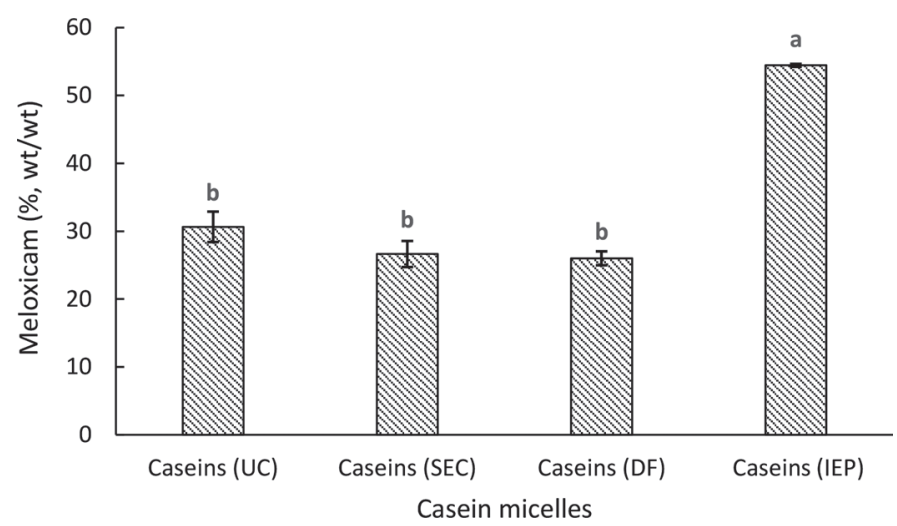

Figure 1. In vivo distribution of meloxicam (MLX) in bovine casein micelles. $\mathrm{UC}=$ ultracentrifugation; $\mathrm{SEC}=$ size exclusion chromatography; $\mathrm{DF}=$ diafiltration; IEP $=$ isoelectric point precipitation. All values are mean $\pm \mathrm{SE}$ with $\mathrm{n}=3$; means followed by same letter $(\mathrm{a}, \mathrm{b})$ are not significantly different using Tukey $(\alpha=0.05)$. API $=$ active pharmaceutical ingredients. on the de novo synthesis of fat globules and proteins into the ducts of the mammary glands. However, the mechanism of loading of hydrophobic API inside the mammary gland in vivo versus in vitro casein micelles is not known.

The raw milk collected from cows dosed with flunixin and thiabendazole showed the presence of metabolites 5-OH-FLU and 5-OH-TBZ as major markers. Flunixin is a weakly acidic hydrophobic API with $\log \mathrm{D}$ value of 3.08. The metabolite $5-\mathrm{OH}-\mathrm{FLU}$ is slightly less hydrophobic than flunixin, due to the presence of hydroxy group on the aromatic ring, with $\log \mathrm{D}$ value of 1.93 at $\mathrm{pH}$ 6.8. Despite the differences in extent of hydrophobicity between flunixin and its metabolites, the evaluation of partitioning of hydrophobic metabolites in various fractions of raw milk would be an important step in understanding the interactions between hydrophobic compounds and native casein micelles. Whole raw milk from dosed cows contained $135 \pm 0.4 \mu \mathrm{g} / \mathrm{L}$ of 5-OH-FLU, with $31.4 \pm 1.3$ and $32 \pm 1.8 \%$ associated with the casein micelle fraction isolated by ultracentrifugation and diafiltration, respectively (Figure 3). In comparison, a higher percent of 5-OH-FLU was found in casein micelles when separated by isoelectric precipitation $(52 \pm 3.6 \%)$. This increase was attributed to the protonation of the carboxylate group on 5-OH-FLU $\left(\mathrm{p} K_{\mathrm{a}} 5.82\right)$ at acidic $\mathrm{pH} 4.6$, resulting in an increase in hydrophobicity and enhancement of the interaction with hydrophobic domains of casein proteins. No significant differences were found in the distribution of

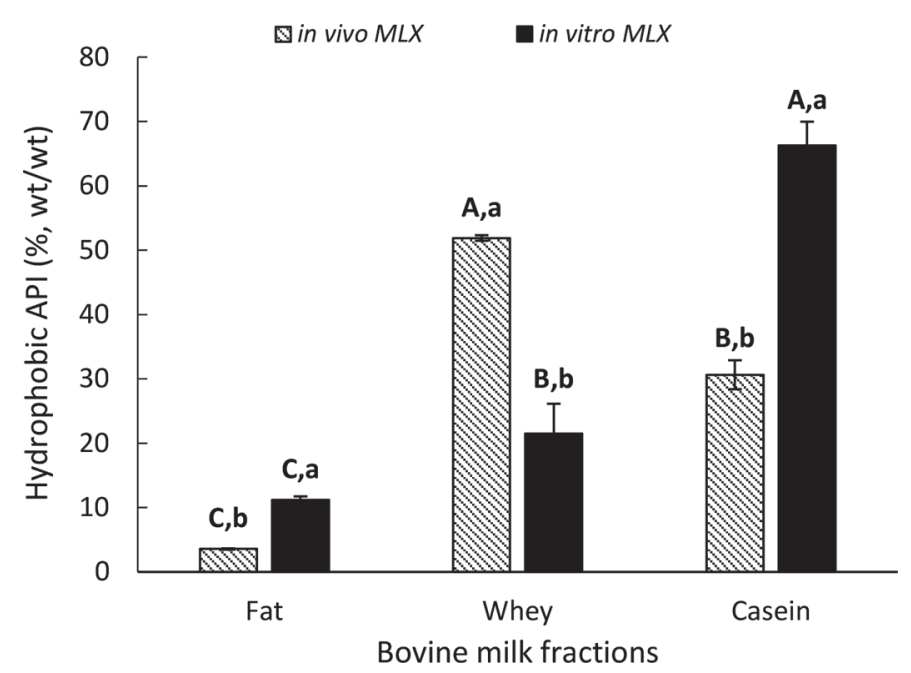

Figure 2. In vivo and in vitro distribution of meloxicam in bovine milk fractions. All values are mean $\pm \mathrm{SE}$ with $\mathrm{n}=3$; means followed by the same uppercase letter $(\mathrm{A}-\mathrm{C})$ are not significant across the fat, whey, and casein fractions using Tukey $(\alpha=0.05)$. Means followed by the same lowercase letter $(\mathrm{a}, \mathrm{b})$ are not significantly different within each fraction. 


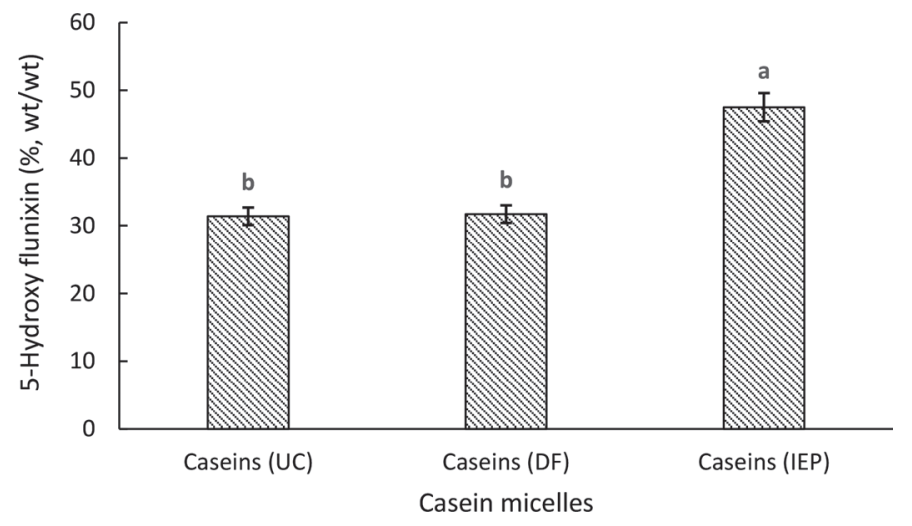

Figure 3. In vivo distribution of 5-hydroxy flunixin (5-OH-FLU) in bovine casein micelles. UC $=$ ultracentrifugation; $\mathrm{DF}=$ diafiltration $\mathrm{IEP}=$ isoelectric point precipitation. All values are mean $\pm \mathrm{SE}$ with $\mathrm{n}=3$; means followed by the same letter $(\mathrm{a}, \mathrm{b})$ are not significantly different using Tukey $(\alpha=0.05)$.

flunixin and 5-OH-FLU in casein proteins and whey fraction in the in vivo versus in vitro studies (Figure 4), and both in vivo and in vitro studies showed a similar percent partition of flunixin and 5-OH-FLU into casein micelles $(\sim 29-30 \%)$. Significant differences were found in distribution of the API in fat fraction with $>5$ and 11 to $18 \%$ associated with the fat fraction in the in vivo and in vitro studies, respectively. The majority of the flunixin and 5-OH-FLU API was found to be associated with the whey (serum) fraction, except for casein

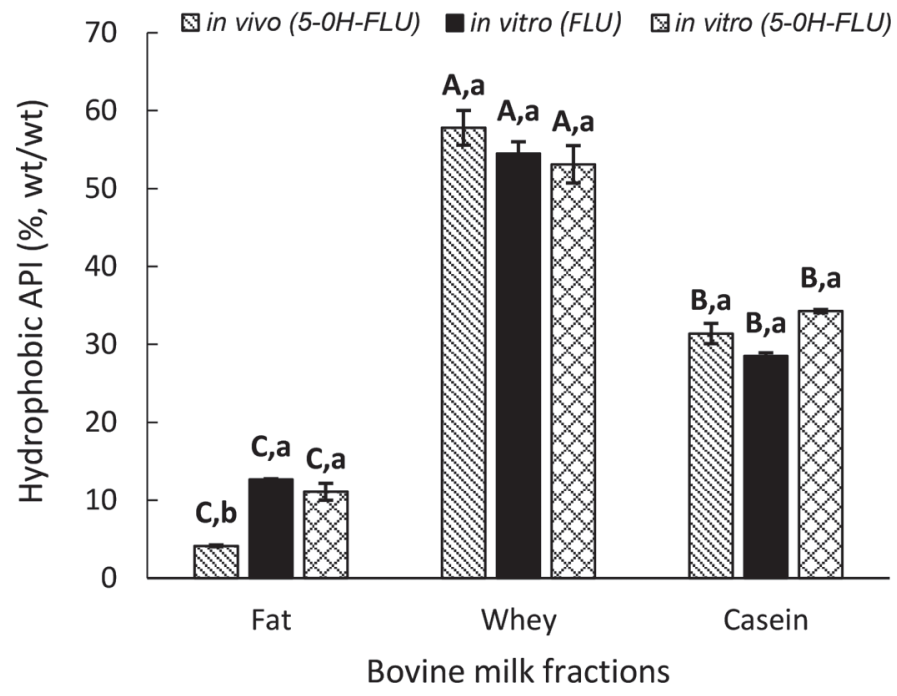

Figure 4. In vivo and in vitro distribution of flunixin (FLU) and 5 -hydroxy flunixin (5-OH-FLU) in bovine milk fractions. All values are mean $\pm \mathrm{SE}$ with $\mathrm{n}=3$; means followed by the same uppercase letter $(\mathrm{A}-\mathrm{C})$ are not significantly different across the fat, whey, and casein fractions using Tukey $(\alpha=0.05)$. Means followed by the same lowercase letter $(a, b)$ are not significantly different within each fraction. $\mathrm{API}=$ active pharmaceutical ingredients. micelles separated by isoelectric precipitation, probably due to the presence of negatively charged carboxylate groups enhancing solubility in aqueous phase and binding to whey proteins in serum. The goal of the current study was to understand the role of native casein micelles in binding hydrophobic compounds. The binding of hydrophobic probes to whey proteins was considered outside the scope of the present study and not tested.

The hydrophobic metabolite 5-OH-TBZ was the major marker for thiabendazole in the in vivo study, and parent compound thiabendazole was not detected. Although thiabendazole and 5-OH-TBZ possess comparable hydrophobicity in terms of $\log \mathrm{D}$ values (i.e., 2.92 and 2.1 at milk pH 6.8, respectively; Table 1), the in vitro analysis for thiabendazole showed higher percentage ( $50 \pm 4.5 \%$; mean $\pm \mathrm{SE}$ ) associated with casein micelles as compared with the in vivo distribution of its metabolite 5 -OH-TBZ $(28 \pm 0.5 \%)$. The 3 methods to isolate the casein micelles from milk showed similar results in the binding of $5-\mathrm{OH}-\mathrm{TBZ}$ to casein micelles (i.e., $28 \pm 0.5 \%$ for ultracentrifugation, $31 \pm 3.2 \%$ for diafiltration, and $27 \pm 3.9 \%$ for isoelectric precipitation; Figure 5). The in vivo results showed that the majority of 5 -OH-TBZ $(55 \pm 2.0 \%)$ partitioned into whey fraction (bound or free), which was similar to the distribution observed in the in vitro study, with $60 \pm 2.80 \%$ of 5-OH-TBZ partitioning to the whey fraction; however, the in vitro distribution of thiabendazole showed only $29 \pm 3.0 \%$ partitioning to the whey fraction (Figure $6)$. Both in vitro and in vivo studies showed similar distribution of 5-OH-TBZ associated with casein proteins $(\sim 30 \%)$, whereas the majority of thiabendazole partitioned to the casein proteins $(50 \pm 4.5 \%)$ during the in vitro studies. Less than $5 \%$ of metabolite $5-\mathrm{OH}-$ TBZ was found to be associated with the fat fraction in both in vitro and in vivo analysis, whereas the in vitro analysis showed that $18 \pm 2.9 \%$ of thiabendazole associated with the fat fraction. Overall, similar trends were found for the metabolite 5-OH-TBZ in both in vivo and in vitro, whereas thiabendazole significantly differed in its distribution among fractions $(P<0.05)$. Although no information is available on partitioning of thiabendazole to milk when API is dosed to lactating cows, similar results were found for the related anthelmintic albendazole, with $30 \%$ of the albendazole metabolite dosed to cows found associated with rennet casein curds and $54 \%$ found associated with the whey fraction (Fletouris et al., 1998).

Although hydrophobic API are expected to partition into the fat fraction of whole milk, the results obtained indicate that hydrophobic API tend to partition preferably to casein proteins or serum (bound or free) as compared with fat. Lower partitioning into fat fraction for thiabendazole is in agreement with a recent study 


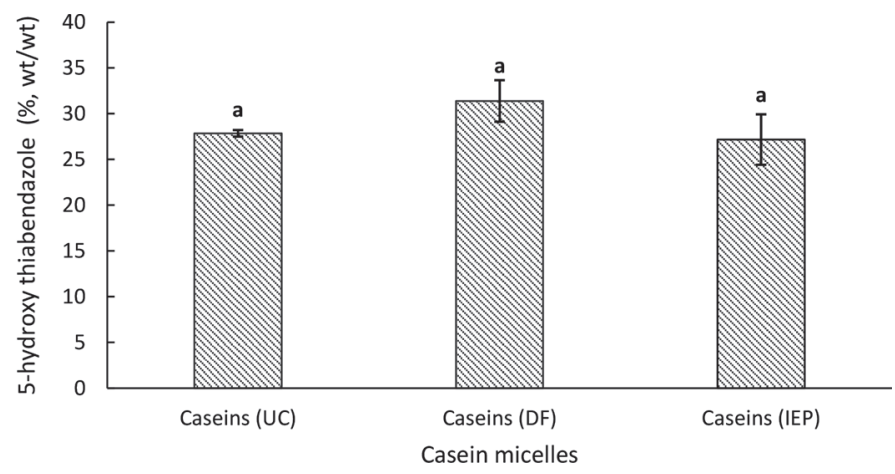

Figure 5. In vivo distribution of 5-hydroxy thiabendazole (5-OHTBZ) in bovine casein micelles. $\mathrm{UC}=$ ultracentrifugation; $\mathrm{DF}=$ diafiltration; IEP = isoelectric point precipitation. All values are mean $\pm \mathrm{SE}$ with $\mathrm{n}=2$; means with a letter (a) are not significantly different using Tukey $(\alpha=0.05)$.

where whole milk was spiked with thiabendazole and the majority of the API partitioned into the skim milk fraction versus the fat fraction (Hakk et al., 2016). The observed lower partition to casein proteins was partially due to the presence of the metabolite 5-OH-TBZ, which is slightly less hydrophobic $(\log \mathrm{D}=2.1)$ than thiabendazole $(\log \mathrm{D}=2.92)$. The hydroxylated hydrophobic API, including flunixin and thiabendazole, leads to enhanced solubility in aqueous serum of the milk and, thus, reduces the partition to hydrophobic sites, including those available in casein micelles. However, the binding to whey proteins was not determined in the

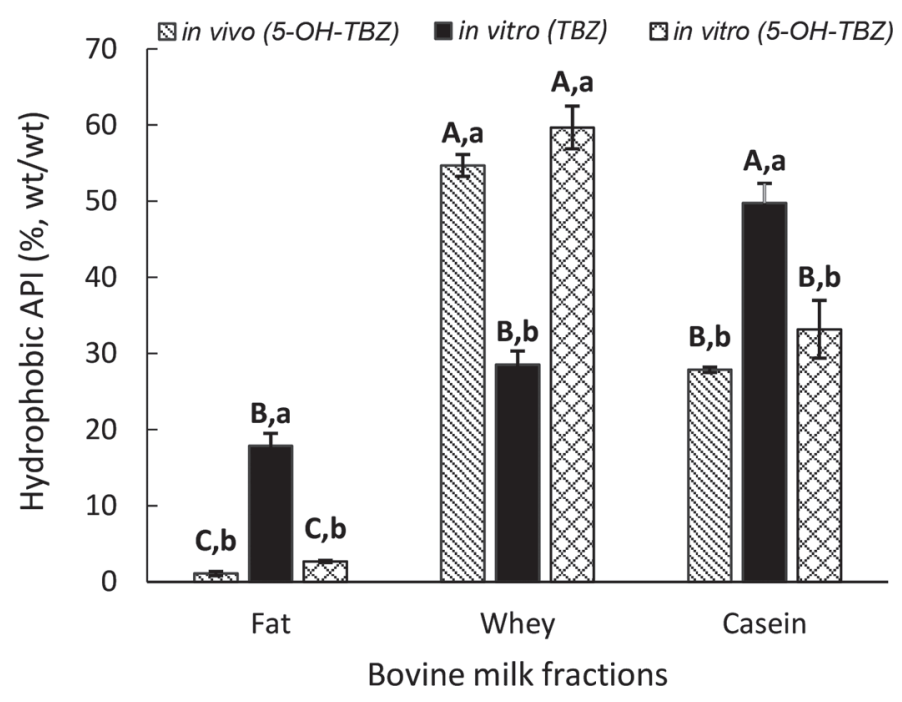

Figure 6. In vivo and in vitro distribution of thiabendazole (TBZ) and 5-hydroxy thiabendazole (5-OH-TBZ) in bovine milk fractions. All values are mean $\pm \mathrm{SE}$ with $\mathrm{n}=2$; means followed by the same uppercase letter $(\mathrm{A}-\mathrm{C})$ are not significantly different across the fat, whey, and casein fractions, using Tukey $(\alpha=0.05)$. Means followed by the same lowercase letter $(a, b)$ are not significantly different within each fraction. API = active pharmaceutical ingredients. current study, so the true partition among proteins is not known.

Differences in trends between meloxicam and thiabendazole in vivo versus in vitro could be due to differences in the mechanism by which the API are loaded into the casein micelles in milk based on their interactions with electrostatic and hydrophobic domains. $\beta$-Casein is located in the internal core of bovine casein micelles, and is known to improve the loading of hydrophobic probes into reassembled casein micelles by providing available domains (Sahu et al., 2008). The quenching of fluorescent Trp residues showed that hydrophobic interactions were dominant in the binding of low molecular probes, and stronger interaction with $\beta$ - versus $\alpha_{S}-\mathrm{CN}$ were reported for the hydrophobic curcumin and polyphenols (Bourassa et al., 2013).

Several studies focused on the protective effect resulting from hydrophobic nutraceuticals and pharmaceuticals binding to reassembled $\beta$-CN protein micelles (Shapira et al., 2010a,b; Bachar et al., 2012; Turovsky et al., 2015). The role of $\beta-\mathrm{CN}$ in the binding properties of native casein micelles is further supported by a previous study, where human milk was spiked with lipid-soluble API and most partitioning occurred in the casein proteins (Stebler and Guentert, 1990). In human milk, $\beta$-CN accounts for $\sim 70 \%$ of all casein content, with $\alpha_{\mathrm{S}^{-}} \mathrm{CN}$ present in trace amounts and $\beta$-LG absent (Farrell et al., 2006).

$\beta$-Caseins are known to reversibly dissociate from the casein micelles at low temperatures and migrate back to the colloidal phase on increasing temperature due to hydrophobic association with the micelles. As the in vivo API distribution studies were done at $37^{\circ} \mathrm{C}$ whereas in vitro studies were done at $25^{\circ} \mathrm{C}, \beta-\mathrm{CN}$ migration out of micelles may have rendered hydrophobic sites available for interactions with API, as observed for meloxicam ( $\sim 66 \%$ binding to the casein fraction) and thiabendazole ( $\sim 50 \%$ binding to the casein fraction). A similar phenomenon was reported, where the removal of $\beta$-CN by cooling enhanced the interactions between casein micelles and the hydrophobic curcumin (Yazdi et al., 2014). Based on the previous studies, $\beta-\mathrm{CN}$ is hypothesized to play a role in providing binding sites for association of hydrophobic API with casein micelles.

\section{CONCLUSIONS}

The in vivo studies showed that $\sim 31,34$, and $28 \%$ of hydrophobic API meloxicam, 5-OH-FLU, and 5-OHTBZ, respectively, associated with casein micelles, whereas less than $5 \%$ of the API were found partitioned into the fat fraction of raw bovine milk and $\sim 50 \%$ partitioned to the whey (serum) fraction (either free or bound to whey proteins). The in vitro study results for 
meloxicam were different $(P<0.05)$ as compared with in vivo results with $\sim 66 \%$ of the API found associated with the casein micelles. The partitioning of flunixin and 5-OH-FLU followed similar trends in the in vivo versus in vitro studies. The partitioning of $5-\mathrm{OH}-\mathrm{TBZ}$ into casein proteins in vivo and in vitro showed similar trends with 28 and $35 \%$, respectively, whereas $50 \%$ of thiabendazole was found associated with the casein proteins. Overall, $\sim 30 \%$ of the hydrophobic API found in milk from dosed lactating cows was associated with casein micelles. Although no linear relationship was found between increased API hydrophobicity (log D) and association to casein micelles, the percent partition of API to casein micelles exceeded that of the fat fraction for all 3 API. The thorough understanding of binding properties of native casein micelles is useful in applications for increasing the net solubility of nutraceuticals in complex food systems or the masking of therapeutic compounds in liquid food systems. Furthermore, the association of hydrophobic API to casein proteins should be accounted when evaluating API residues in bovine milk. This study demonstrates that the open structure and available sites for interaction allow the native casein micelles to incorporate low-molecular-weight hydrophobic compounds. It appears that the transport of hydrophobic molecules from mother to young is a biological role of casein micelles in milk beyond transporting calcium.

\section{ACKNOWLEDGMENTS}

We thank Nadine Houck and Travis Edwards, of The Pennsylvania State University dairy barns (University Park), for helping in administration of API to the cows and collection of raw milk samples. We thank Jacob Werner, Department of Veterinary and Biomedical Sciences, The Pennsylvania State University, for helping us ordering the entire API used in the study. We are grateful to Joshua Lambert, Department of Food Science, The Pennsylvania State University, for extensively helping us with instrumentation (HPLC) needed for quantitative analysis of the API. We acknowledge the support by the College of Agricultural Sciences, Pennsylvania State University.

\section{REFERENCES}

Atamer, Z., A. E. Post, T. Schubert, A. Holder, R. M. Boom, and J. Hinrichs. 2017. Bovine $\beta$-casein: Isolation, properties and functionality. A review. Int. Dairy J. 66:115-125.

Bachar, M., A. Mandelbaum, I. Portnaya, H. Perlstein, S. Even-Chen, Y. Barenholz, and D. Danino. 2012. Development and characterization of a novel drug nanocarrier for oral delivery, based on selfassembled $\beta$-casein micelles. J. Control. Release 160:164-171.
Bourassa, P., J. Bariyanga, and H. A. Tajmir-Riahi. 2013. Binding sites of resveratrol, genistein, and curcumin with milk $\alpha$ - and $\beta$-caseins. J. Phys. Chem. B 117:1287-1295.

Cerkvenik, V., B. Perko, I. Rogelj, D. Doganoc, V. Skubic, W. Beek, and H. Keukens. 2004. Fate of ivermectin residues in ewes' milk and derived products. J. Dairy Res. 71:39-45.

Cheema, M., M. S. Mohan, S. R. Campagna, J. L. Jurat-Fuentes, and F. M. Harte. 2015. The association of low-molecular-weight hydrophobic compounds with native casein micelles in bovine milk. J. Dairy Sci. 98:5155-5163.

Chen, D., Y. Tao, Z. Liu, Z. Liu, L. Huang, Y. Wang, Y. Pan, D. Peng, M. Dai, and Z. Yuan. 2010. Development of a high-performance liquid chromatography method to monitor the residues of benzimidazoles in bovine milk. J. Chromatogr. B Analyt. Technol. Biomed. Life Sci. 878:2928-2932.

Corzo-Martínez, M., M. Mohan, J. Dunlap, and F. Harte. 2015. Effect of ultra-high pressure homogenization on the interaction between bovine casein micelles and ritonavir. Pharm. Res. 32:1055-1071.

Dalgleish, D. G. 2011. On the structural models of bovine casein micelles-Review and possible improvements. Soft Matter 7:22652272 .

de Kruif, C. G., T. Huppertz, V. S. Urban, and A. V. Petukhov. 2012 Casein micelles and their internal structure. Adv. Colloid Interface Sci. 171-172:36-52.

Farrell, H. M., E. L. Malin, E. M. Brown, and P. X. Qi. 2006. Casein micelle structure: What can be learned from milk synthesis and structural biology? Curr. Opin. Colloid Interface Sci. 11:135-147.

Fletouris, D. J., N. Botsoglou, I. Psomas, and A. Mantis. 1998. Albendazole-related drug residues in milk and their fate during cheesemaking, ripening, and storage. J. Food Prot. 61:1484-1488.

Food Animal Residue Avoidance Databank. 2016. Component of Food Animal Residue Avoidance \& Depletion Program. Accessed Aug. 20, 2014. http://www.farad.org/wdilookup/.

Forrest, S. A., R. Y. Yada, and D. Rousseau. 2005. Interactions of vitamin D3 with bovine $\beta$-lactoglobulin A and $\beta$-casein. J. Agric. Food Chem. 53:8003-8009.

Fox, P. F., and A. Brodkorb. 2008. The casein micelle: Historical aspects, current concepts and significance. Int. Dairy J. 18:677-684.

Hakk, H., N. W. Shappell, S. J. Lupton, W. L. Shelver, W. Fanaselle, D. Oryang, C. Y. Yeung, K. Hoelzer, Y. Ma, D. Gaalswyk, R. Pouillot, and J. M. Van Doren. 2016. Distribution of animal drugs between skim milk and milk fat fractions in spiked whole milk: understanding the potential impact on commercial milk products. J. Agric. Food Chem. 64:326-335.

Holt, C., J. A. Carver, H. Ecroyd, and D. C. Thorn. 2013. Invited review: Caseins and the casein micelle: Their biological functions, structures, and behavior in foods. J. Dairy Sci. 96:6127-6146.

Jedziniak, P., T. Szprengier-Juszkiewicz, and M. Olejnik. 2009a. Inhouse reference materials: 5-hydroxyflunixin and meloxicam in cow milk-Preparation and evaluation. Anal. Chim. Acta 637:346-350.

Jedziniak, P., T. Szprengier-Juszkiewicz, and M. Olejnik. 2009b. Multi-residue screening method for the determination of non-steroidal anti-inflammatory drug residues in cow's milk with HPLCUV and its application to meloxicam residue depletion study. Bull. Vet. Inst. Pulawy 53:731-739.

Kimpel, F., and J. J. Schmitt. 2015. Review: Milk proteins as nanocarrier systems for hydrophobic nutraceuticals. J. Food Sci. 80:R2361-R2366.

Kissell, L. W., G. W. Smith, T. L. Leavens, R. E. Baynes, H. Wu, and J. E. Riviere. 2012. Plasma pharmacokinetics and milk residues of flunixin and 5-hydroxy flunixin following different routes of administration in dairy cattle. J. Dairy Sci. 95:7151-7157.

Livney, Y. D. 2010. Milk proteins as vehicles for bioactives. Curr. Opin. Colloid Interface Sci. 15:73-83.

Mohan, M. S., J. L. Jurat-Fuentes, and F. Harte. 2013. Binding of vitamin A by casein micelles in commercial skim milk. J. Dairy Sci. 96:790-798.

Pan, K., Y. Luo, Y. Gan, S. J. Baek, and Q. Zhong. 2014. pH-driven encapsulation of curcumin in self-assembled casein nanoparticles for enhanced dispersibility and bioactivity. Soft Matter 10:68206830 . 
Puyol, P., M. D. Perez, J. Manuel, and M. Calyo. 1991. Interaction boyine $\beta$-lactoglobulin in and other bovine human whey proteins with retinol and fatty acids. Agric. Biol. Chem. 55:2515-2520.

Sahu, A., N. Kasoju, and U. Bora. 2008. Fluorescence study of the curcumin-casein micelle complexation and its application as a drug nanocarrier to cancer cells. Biomacromolecules 9:2905-2912.

Semo, E., E. Kesselman, D. Danino, and Y.D. Livney. 2007. Casein micelle as a natural nano-capsular vehicle for nutraceuticals. Food Hydrocoll. 21:936-942.

Shapira, A., Y. G. Assaraf, D. Epstein, and Y. D. Livney. 2010a. Betacasein nanoparticles as an oral delivery system for chemotherapeutic drugs: Impact of drug structure and properties on co-assembly. Pharm. Res. 27:2175-2186.

Shapira, A., Y. G. Assaraf, and Y. D. Livney. 2010b. Beta-casein nanovehicles for oral delivery of chemotherapeutic drugs. Nanomedicine 6:119-126.

Shappell, N. W., W. L. Shelver, S. J. Lupton, W. Fanaselle, J. M. Van Doren, and H. Hakk. 2017. Distribution of animal drugs among curd, whey, and milk protein fractions in spiked skim milk and whey. J. Agric. Food Chem. 65:938-949.

Stebler, T., and T. w. Guentert. 1990. Binding of drugs in milk: The role of casein in milk protein binding. Pharm. Res. 7:633-637.

Su, S. C., C. L. Chang, P. C. Chang, and S. S. Chou. 2003. Simultaneous determination of albendazole, thiabendazole, mebendazole and their metabolites in livestock by high performance liquid chromatography. J. Food Drug Anal. 11:307-319.

Trejo, R., T. Dokland, J. Jurat-Fuentes, and F. Harte. 2011. Cryotransmission electron tomography of native casein micelles from bovine milk. J. Dairy Sci. 94:5770-5775.

Turovsky, T., R. Khalfin, S. Kababya, A. Schmidt, Y. Barenholz, and D. Danino. 2015. Celecoxib encapsulation in $\beta$-Casein micelles: Structure, interactions, and conformation. Langmuir 31:7183-7192.

Yazdi, S. Y., M. Corredig, and D. G. Dalgleish. 2014. Studying the structure of $\beta$-casein-depleted bovine casein micelles using electron microscopy and fluorescent polyphenols. Food Hydrocoll. 42:171-177. 